\title{
Erratum: Arfan M., et al. Assessment of Spatial and Temporal Flow Variability of the Indus River. Resources 2019, 8, 103
}

\author{
Muhammad Arfan ${ }^{1, *(D)}$, Jewell Lund ${ }^{2}$, Daniyal Hassan ${ }^{3} \mathbb{D}$, Maaz Saleem $^{1}$ and Aftab Ahmed ${ }^{1}$ \\ 1 USPCAS-W, MUET Sindh, Jamshoro 76090, Pakistan \\ 2 Department of Geography, University of Utah, Salt Lake City, UT 84112, USA \\ 3 Department of Civil \& Environmental Engineering, University of Utah, Salt Lake City, UT 84112, USA \\ * Correspondence: mapiish37@gmail.com; Tel.: +92-346770908, +1-801-815-1679
}

The authors wish to make the following corrections to the published paper [1]:

The author's name Aftab Ahmad should be corrected as Aftab Ahmed.

The authors and the Editorial Office would like to apologize for any inconvenience caused to the readers by these changes. The change does not affect the scientific results. The manuscript will be updated and the original will remain online on the article webpage.

\section{Reference}

1. Arfan, M.; Lund, J.; Hassan, D.; Saleem, M.; Ahmad, A. Assessment of Spatial and Temporal Flow Variability of the Indus River. Resources 2019, 8, 103. [CrossRef]

(C) 2019 by the authors. Licensee MDPI, Basel, Switzerland. This article is an open access article distributed under the terms and conditions of the Creative Commons Attribution (CC BY) license (http://creativecommons.org/licenses/by/4.0/). 